\title{
O desafio da orientação profissional com adolescentes no contexto da modernidade líquida
}

\author{
The challenge of adolescents' vocational guidance in the context of \\ liquid modernity
}

http://dx.doi.org/10.5007/2178-4582.2014v48n2p263

\author{
Mariana Moura dos Santos, Iúri Novaes Luna e Marucia Patta Bardagi \\ Universidade Federal de Santa Catarina, Florianópolis/SC, Brasil
}

\begin{abstract}
Este artigo propõe uma discussão acerca do processo de orientação profissional com adolescentes sob a ótica da modernidade líquida. Segundo esta perspectiva, as características principais da modernidade são a efemeridade, o distanciamento e a superficialidade de conhecimento e entendimento dos sujeitos acerca do mundo e de si mesmos, geradas pelos impedimentos e pela falta de estímulo à reflexão. Este espírito de desapego e descompromisso pode trazer dificuldades no planejamento profissional e de vida, seja na adolescência ou mais adiante, pois pensar no próprio futuro e tomar decisões sobre ele implica autoconhecimento, percepção de estabilidade de certos interesses e metas pessoais e estabelecimento de estratégias de longo prazo. Nesse sentido, as implicações das características da modernidade líquida nos resultados e na própria concepção dos processos de orientação profissional são discutidas ao longo do texto.
\end{abstract}

Palavras-chave: Adolescentes - Orientação Profissional - Modernidade Líquida
This paper proposes a discussion on the process of career guidance with adolescents under the perspective of liquid modernity. In this view, the main features of modernity are the ephemerality, the distance and the superficiality of knowledge and understanding of the subjects about the world and about themselves, generated by impediments and lack of stimulus for reflection. This spirit of detachment and disengagement can bring difficulties in planning personal and professional life, either in adolescence or later, precisely because thinking about one's future and make decisions about it implies self-knowledge, perception of stability of certain interests and personal goals and establishing long-term strategies. In this sense, the implications of the characteristics of liquid modernity on the results and in the very conception of the processes of vocational guidance are discussed throughout the text.

Keywords: Adolescents - Vocational Guidance Liquid Modernity

\section{Introdução}

O presente artigo propõe uma discussão, sob a ótica da modernidade líquida, acerca dos processos de orientação profissional com adolescentes, nos quais muitas vezes observam-se níveis superficiais de conhecimento sobre os cursos e profissões almejadas, assim como sobre si próprios (em termos de seus interesses, valores e habilidades) (PRIMI et. al. 2000; SCHIESSE; SARRIERA, 2000; SPARTA; BARDAGI; ANDRADE, 2005). A modernidade líquida é um fenômeno descrito inicialmente pelo sociólogo Zygmunt Bauman (1999; 2001), que corresponde às características de efemeridade, fluidez e 
falta de comprometimento presentes no mundo contemporâneo. Ressalta-se que este trabalho, certamente, não tem a pretensão de esgotar esta temática, mas propor uma reflexão sobre a mesma em termos do impacto destas características da modernidade nos processos de orientação e escolha profissional. As principais motivações para esta reflexão teórica vêm da observação da dificuldade de sujeitos em processo de escolha profissional em estabelecer prioridades e hierarquias de interesses, em pensar sobre si mesmos no futuro, em comprometer-se com valores pessoais e projetos de vida (PRIMI et. al., 2000; SCHIESSE; SARRIERA, 2000; SPARTA et al., 2005), além da constatação dos altos índices de evasão universitária e busca por trocas de curso em fases iniciais da graduação (BARDAGI; HUTZ, 2009; FILHO et. al., 2007; PAREDES 1994), dados que sugerem escolhas iniciais pouco refletidas ou inconsistentes.

Quanto à dificuldade apresentada pelos indivíduos em processo de escolha profissional, em um estudo realizado por Sparta e colaboradores (2005), com 59 vestibulandos, a maior parte deles não foi capaz de identificar de forma clara suas dificuldades diante da escolha profissional. Este resultado foi interpretado como um possível reflexo da insuficiência de comportamentos exploratórios e reflexões acerca de diferentes aspectos relacionados à escolha de uma profissão a ser seguida, já que para ter clareza sobre as próprias dificuldades de escolha é necessário que o indivíduo tenha certo nível de autoconhecimento e conhecimento sobre o mundo do trabalho. Primi e colaboradores (2000), ao realizarem um estudo para a construção do Inventário das Dificuldades de Decisão Profissional (IDDP), observaram que dentre os principais fatores relacionados às dificuldades de escolha estavam: a imaturidade, a insegurança e a falta de informação. Schiesse e Sarriera (2000), em uma pesquisa realizada com alunos do terceiro ano do ensino médio de escolas públicas e particulares da cidade de Itajaí (SC), também identificaram que fatores como a imaturidade e a dificuldade para identificar os próprios interesses e aptidões estavam dentre aqueles que mais dificultavam a escolha por um curso universitário. Faria e Guzzo (2007), ao analisarem as representações sociais de adolescentes sobre profissão, trabalho e emprego, observaram que os jovens têm feito suas escolhas usando informações imprecisas sobre a carreira que desejam seguir; os autores encontraram ainda, entre os alunos de escola privada, uma maior preocupação do que os alunos de escola pública em atender suas próprias expectativas e necessidades, sem atribuir ao trabalho uma dimensão coletiva. No estudo de Soares (2007) com 655 participantes, que buscou identificar as principais razões para a escolha do curso superior, verificou-se que a maioria dos adolescentes e jovens pesquisados realizou sua escolha às vésperas do vestibular, sem planejamento prévio. 
No que diz respeito à evasão universitária, o estudo realizado por Paredes (1994) com 145 alunos de diferentes cursos de duas universidades nacionais apontou que $26,2 \%$ dos participantes alegaram como motivos para a evasão do ensino superior um dos seguintes tópicos: vocação errada, informações prévias insuficientes ou imaturidade. Bardagi e Hutz (2009), ao pesquisarem a percepção de alunos evadidos de cursos superiores, identificaram que as escolhas iniciais destes haviam sido frágeis, pautadas em pouca atividade exploratória e em visões irrealistas das profissões e respectivas carreiras. Recentemente, Lehman (2014), ao analisar 180 casos atendidos de estudantes universitários em re-escolha profissional, também observou que uma das causas principais para o abandono de curso é a falta de elaboração e consistência das escolhas iniciais feitas na adolescência. Esses dados confirmam a vulnerabilidade das decisões profissionais tomadas na adolescência e o espaço existente para que se pense a prática de orientação profissional como intervenção favorecedora destas decisões. Embora essas percepções sobre as escolhas na adolescência e a orientação profissional não sejam recentes, discussões a respeito das relações entre tais temas no contexto da modernidade líquida parecem fazer ainda mais sentido.

\section{A fluidez da modernidade líquida e a globalização}

A contemporaneidade pode ser caracterizada, em grande parte, pela imposição de vivências aceleradas, dinâmicas, fluidas e efêmeras, compreendidas por Bauman (2001) em seu conceito de modernidade líquida. Tais características influem no comportamento dos sujeitos, permitindo e até mesmo incentivando a construção de determinados tipos de subjetividade que melhor respondam às exigências atuais. Contudo, para problematizar os processos de orientação profissional sob a ótica da denominada modernidade líquida, é necessário contextualizá-los no movimento de modernização da sociedade que, desde o último quarto do século XX, se encontra vinculado aos processos de globalização. A modernidade, caracterizada por instituições e modos de comportamento observados inicialmente na Europa após o feudalismo, tornou-se mundial em seu impacto no decorrer no século XX, possuindo como aspectos fundamentais o industrialismo, o capitalismo, o aumento fantástico da capacidade destrutiva potencial dos armamentos, o desenvolvimento do estado-nação, a ascensão das estruturas organizacionais e um extremo dinamismo, que configura o mundo moderno como um "mundo em disparada" (GIDDENS, 2002, p.21). Nessa direção, à medida que a modernidade avança, suas características tornam-se mais intensas; a busca incessante pelo aumento da produtividade e da competitividade evidencia o contínuo, porém sempre incompleto, processo de modernização (BAUMAN, 2001). 
Um dos elementos marcantes do caráter dinâmico da vida social moderna é a constante revisão, orientada por novos conhecimentos e informações, das atividades sociais e das relações materiais com a natureza; ou seja, o aparecimento de uma forma distinta de monitoramento reflexivo da ação pode ser entendido com um traço da modernidade. Em contextos pré-modernos, a tradição garantia um referencial ontológico e de ação. À proporção que os caminhos pré-definidos pela tradição vão se tornando cada vez mais raros com o avanço da modernidade, referenciais seguros evidenciados em expressões tais como "é isto que se deve fazer", "fazer o que tem que ser feito" ou "isto é o certo" vão se tornando mais rarefeitos. $\mathrm{O}$ eu torna-se um projeto reflexivo, conectando mudanças pessoais e sociais, assim sendo, "a vida dos homens e mulheres modernos é uma tarefa, não algo determinado" (BAUMAN, 2001, p.155). Todavia, isso não significa que toda a ação humana na modernidade tornou-se guiada por propósitos ou motivos premeditados, uma vez que a capacidade das pessoas realizarem coisas transcende as intenções que elas têm ao fazê-las (GIDDENS, 1989). Nesse aspecto, a história humana constrói-se por meio de uma dialética do intencional e do não-intencional (CORCUFF, 2001).

No que se refere especificamente à relação das pessoas com o mundo do trabalho, a modernidade é marcada pela substituição dos "estamentos", entendidos como lugares a que se pertencia por hereditariedade, pelas "classes", cujo pertencimento acontece em função de realizações pessoais cotidianamente renovadas e reconfirmadas (pertencimento fabricado) (BAUMAN, 2001, p.155). Para ascender à determinada "classe", as pessoas desenvolvem, como ideal de ego, o "desejo de se destacar dos outros, de se sustentar nos próprios pés e de buscar a realização de uma batalha pessoal em suas próprias qualidades, aptidões, propriedades ou realizações" (ELIAS, 1994, p.118). Ainda assim, as chances de alcançar tais objetivos são muito reduzidas em relação ao expressivo número de pessoas que os almejam.

Não obstante o fato de nos tempos atuais ainda se viver na modernidade, é possível observar que a sociedade a partir das últimas décadas do século XX é moderna "de um modo diferente". Nesse sentido, identificam-se dois momentos distintos no movimento de modernização da sociedade, denominados por Bauman (2001) de modernidade sólida e modernidade líquida. Como características da primeira, o autor aponta que "ela parece 'pesada' (contra a 'leve' modernidade contemporânea); ou melhor, ainda 'sólida' (e não 'fluida', 'líquida' ou 'liquefeita'); condensada (contra difusa ou 'capilar'); e, finalmente, 'sistêmica' (por oposição a 'em forma de rede')" (BAUMAN, 2001, p. 33). A crença em um telos alcançável, expresso através de um estado de perfeição - algum tipo de sociedade boa, justa e sem conflitos - a ser atingido no futuro, aparece, ainda, como uma marca da modernidade pesada. 
Em razão da crise financeira da década de 1970, os investidores, em especial os dos países capitalistas centrais, passaram a expandir seus negócios para outros mercados - principalmente os ditos emergentes, que requeriam menor investimento de capital (impostos menores, mão de obra mais barata, etc.) - e a buscar mercados consumidores maiores ou menos saturados que os de seus países (PRADO, 2001). Junto ao processo de globalização econômica, as inovações tecnológicas do final do século XX e início do século XXI proporcionaram maior facilidade para que as pessoas se locomovessem e principalmente se comunicassem, fazendo com que a globalização atingisse com maior impacto as esferas não só econômicas e políticas, mas sociais e culturais. A aceleração e a fluidez atuais estariam associadas também às inúmeras exigências que circulam em nossa sociedade, de intensa produtividade e consumo, a fim de movimentar a economia a favor dos investidores (novos detentores dos meios de produção). Estas exigências teriam tornando o tempo mais curto e as oportunidades de reflexão mais escassas, e se instalado de forma cada vez mais imperiosa nas sociedades contemporâneas, repercutindo no comportamento e na subjetividade dos sujeitos que nela vivem (HAROCH, 2004; PRADO, 2001; SENNETT, 2002; SENNETT, 2008).

Desse modo, "as sociedades contemporâneas, sob o impacto da globalização, tendem a se tornar sociedades que se transformam de maneira contínua, sociedades flexíveis, sem fronteiras e sem limites, sociedades fluidas, sociedades líquidas" (HAROCH, 2004, p.223). Com a emergência da modernidade líquida, associada aos processos de globalização, os indivíduos, cronicamente desacomodados, não encontram lugares para a reacomodação e, assim, estão sempre em movimento, sem nenhuma garantia de alcançar o objetivo final, de poder desarmar-se e relaxar. Como afirma Giddens (2002), a alta modernidade (expressão utilizada pelo autor para designar o atual momento histórico) impõe a todos os indivíduos um processo de "encontrar-se a si mesmo"; não se pode viver no "piloto automático" nem estar "à vontade" no mundo. Nesse cenário, perguntas tais como "O que fazer? Como agir? Quem ser?" assumem uma posição central e precisam ser respondidas, "seja discursivamente, seja no comportamento do dia-a-dia.” (GIDDENS, 2002, p. 70).

Contudo, as mudanças no mundo do trabalho não atingem todos os sujeitos da mesma forma. Para aqueles que ocupam o topo da pirâmide de poder do capitalismo leve, que dominam a arte de "viver no labirinto" (BAUMAN, 2001), a precariedade, a instabilidade e a hibridez geralmente assumem valores positivos. Entretanto, para grande parte dos indivíduos, este cenário, estando associado muitas vezes à falta de trabalho e emprego ou a trabalhos precários e informais, tem como consequência a construção de vidas frágeis 
e incertas. Sobre as desigualdades presentes no processo de modernização da sociedade, Giddens evidencia que:

\begin{abstract}
Na modernidade tardia, o acesso aos meios de auto-realização torna-se em si mesmo um dos focos dominantes da divisão de classes e da distribuição das desigualdades em geral. O capitalismo, uma das principais forças por trás da expansão da modernidade, é um sistema de classes que tende a gerar grandes desigualdades materiais - tanto na escala global quanto dentro das sociedades economicamente desenvolvidas (GIDDENS, 2002, p. 209).
\end{abstract}

Sendo o presente instável e flexível, a integração do futuro nas estratégias e planos de vida só pode ser de curto prazo, e o significado desse fato em termos de autorrealização e qualidade de vida depende, de forma significativa, da posição ocupada pelo sujeito no contexto socioeconômico, nas pirâmides de poder do capitalismo. Na contemporaneidade, vive-se a experiência combinada da falta de garantias (quanto à posição social, aos títulos adquiridos e à sobrevivência), da incerteza (em relação ao futuro) e da insegurança (no que se refere à própria identidade). Nesse cenário, o adiamento da satisfação em nome de projetos futuros - ou, nas palavras de Giddens (2002), "momentos de parada" para perceber novas demandas e novas possibilidades - muitas vezes perde o sentido, o que faz a política da satisfação instantânea parecer uma estratégia razoável. As oportunidades devem ser aproveitadas logo que surgem, sendo "agora" a palavra-chave da estratégia de vida. O mundo social configura-se como um agregado de produtos para o consumo imediato.

Diante disso, como é possível "pensar imerso na fluidez, sob a pressão permanente e ininterrupta do fluxo? O indivíduo hipermoderno pode, privado de tempo, da duração exigida pelos sentimentos, experimentar outra coisa além de sensações?" (HAROCH, 2004, p.223). Toda essa fluidez, esse movimento contínuo, ao mesmo tempo em que exige respostas constantes, dificulta o exercício da reflexão, a elaboração das percepções advindas das sensações (Ibid.). Desse modo, a subjetividade contemporânea pode ser caracterizada pela falta de engajamento; o sujeito encontra-se "ligado, mas distante". Além da distância e da superficialidade de conhecimento e entendimento acerca do mundo e de si mesmos, geradas pelos impedimentos e pela falta de estímulo à reflexão, os sujeitos inseridos na modernidade líquida apresentam ainda certo espírito de desapego e descompromisso, o qual impede a criação de vínculos que, caso ocorressem, poderiam fornecer diferentes benefícios a esses sujeitos, tanto do ponto de vista individual, como em uma perspectiva coletiva.

A solidez das instituições sociais vem, rapidamente, cedendo ao fenômeno da liquefação e, por meio dessa metáfora, Bauman (2001) indica que vivemos 
em um tempo de transformações sociais aceleradas, nas quais a dissolução dos laços sociais e também afetivos é cada vez mais evidente. Os relacionamentos ganham um aspecto utilitarista e os laços, fragilmente construídos, podem ser facilmente desfeitos ao menor desagrado de algum de seus lados. Assim, não se tem segurança sobre a presença ou o apoio do outro, nem se constrói algo consistente conjuntamente. O termo líquido representa esse caráter fluido, efêmero e desapegado dos relacionamentos (sejam eles com pessoas ou coisas), que traz em seu bojo a ideia de uma suposta sensação de leveza e liberdade e, ao mesmo tempo, em seu avesso, revela o desamparo afetivo e social em que se encontra o sujeito contemporâneo.

A estruturação de planos de vida nessas condições (curto prazo, falta de apoio social e afetivo, política da satisfação instantânea) emerge como um desafio considerável e, sendo o trabalho um elemento básico para a construção dos planejamentos estratégicos da vida, o campo da orientação profissional, enquanto um momento de parada (no sentido indicado por Giddens), não pode se furtar a esse debate. Como orientar os indivíduos, especialmente os jovens, nesse novo momento da modernidade? Em um momento no qual se observa uma tendência de mudança de estado do trabalho: de sólido, quando assumia o compromisso com a construção da ordem e com o controle do futuro - sendo produto de planejamentos e projetos - para líquido, escorregando em direção ao reino do jogo, onde o importante são os efeitos imediatos de cada movimento.

Na perspectiva apontada por Bauman (2001), o mundo do trabalho, assim como a vida humana na modernidade fluida, passou a ser uma sequência de episódios, uma constante tentativa de agarrar oportunidades imediatas. O trabalho, nessas condições, passa a ser avaliado principalmente em função de sua capacidade de satisfazer as necessidades e os desejos estéticos do consumidor. "Raramente se espera que o trabalho 'enobreça' os que o fazem, fazendo deles 'seres humanos melhores', e raramente alguém é admirado e elogiado por isso" (BAUMAN, 2001, p. 161). A estética do consumo assume em grande parte, na modernidade fluida, o lugar da ética do trabalho que preconiza o adiamento da satisfação e proclama a virtude do trabalho pelo trabalho. A ética do trabalho corresponde ao estágio sólido - de produtor - da modernidade, enquanto que estética do consumo corresponde ao seu estágio líquido - de consumidor. Em um contexto no qual o curto prazo, a flexibilidade e a incerteza dão o tom, torna-se necessário questionar a relevância de se projetar cenários de trabalho em longo prazo, bem como de se estabelecer caminhos para alcançá-los, como propõem os métodos correntes de orientação profissional.

Atualmente, a necessidade de estar preparado para mudar de atividade a qualquer momento (flexibilidade) cria uma significativa dificuldade para mui- 
tas pessoas afirmarem "é isso que eu faço", para manterem o sentido de um ofício que se exerce. Considerando o momento contemporâneo, "como pode um ser humano desenvolver uma narrativa de identidade e história de vida numa sociedade composta de episódios e fragmentos?" (SENNETT, 2002, p. 27); como os sujeitos estão construindo suas autobiografias e seus planos de vida neste contexto de futuro incerto?

\section{Adolescência, modernidade líquida e as novas tecnologias}

A adolescência historicamente é entendida como um momento crítico do desenvolvimento humano, um momento de muitas mudanças que compreendem questões de caráter biopsicológico e sociocultural (ERIKSON, 1976; KNOBEL, 1981; OLIVEIRA, 2006). Para Oliveira (2006), a adolescência é um período de intenso desenvolvimento do self e, ao contrário da infância, em que a identificação como imitação constitui o principal dispositivo de socialização, na adolescência ganha maior importância a diferenciação, tendência responsável pela enfática afirmação das marcas culturais típicas de cada geração. Segundo a autora, a época contemporânea apresenta algumas questões ao desenvolvimento do self adolescente, como, por exemplo, o "não tempo no imediatismo do prazer e da passagem ao ato, e o tempo ambíguo da falta de tempo para aprender, para a conquista de formas responsáveis de autonomia, para esperar a vez" (OLIVEIRA, 2006, p. 434).

Alguns modelos utilizados para descrever a atual adolescência fazem referência a estas características do imediatismo, da efemeridade, da superficialidade contemporâneas descritos por Bauman (2001) e Haroch (2004), como o termo geração zapping (geração Z), usado, por exemplo, por Levenfus (2002). O termo zapping, do inglês, se refere ao comportamento de zapear que é característico dessa geração, o qual se refere à alternância muito frequente entre atividades ou atenção a diferentes estímulos. Os indivíduos da geração $\mathrm{Z}$ são descritos como capazes de assistir filmes, ouvir música, falar ao telefone, usar a internet, enfim, fazer inúmeras atividades ao mesmo tempo, ou então ficar pulando rapidamente de uma coisa para outra, como, por exemplo, mudar de canal ou página da internet constantemente. Com esse comportamento, os jovens diversificam, mas não necessariamente se aprofundam nas informações com as quais entram em contato, o que pode ocorrer também com relacionamentos, fontes de entretenimento e em outros contextos diversos. Em um texto que reflete sobre as implicações da sociedade do consumo sobre as produções de sentido de adolescentes do Ensino Médio, Oliveira e Tomazetti (2012) apontam uma tendência dos adolescentes atuais de serem resistentes a construções de sentido que vejam o aprendizado dentro de um projeto de longo prazo, gerando adesões distanciadas à escola e o predomínio de uma 
cultura da diversão nos espaços escolares. Para os autores, hoje jovens e adolescentes são sujeitos que transferem para suas relações sociais as operações de uma subjetividade marcada pelas características da sociedade de consumo: rapidez nos vínculos afetivos, preferência por experiências que tragam felicidade imediata, descompromisso com projetos de longo prazo e assunção de identidades flexíveis.

No que diz respeito mais diretamente à informação, nas últimas décadas nota-se um surpreendente avanço exponencial das tecnologias comunicacionais e informacionais, sendo que, dentre estas, a internet assume uma posição de destaque. Segundo Baptista Neto (2011), as informações obtidas por meio da internet permitem a muitos adolescentes que estes criem certa intimidade com a globalização, ampliando desse modo o conceito de mundo que possuem e adaptando-se mais rapidamente às características da sociedade atual. Desse modo, observa-se a emergência, desde as últimas décadas do século XX, de uma geração de "nativos digitais" (PRENSKY, 2001) que, ao crescer com as novas tecnologias (computadores, games, tocadores de música digitais, telefone celulares entre outros brinquedos e ferramentas da era digital), para além da utilização de novas gírias, roupas, adornos corporais e estilos (como ocorreu entre as gerações anteriores), manifesta uma verdadeira e significativa descontinuidade. De acordo com Prensky (2001), a forma de pensar e processar informações mudou: eles são falantes nativos da linguagem digital dos computadores, videogames e internet. Nesse sentido, o desafio para os "imigrantes digitais" - que não nasceram no mundo digital, mas que em algum momento da vida adotaram as novas tecnologias - é justamente compreender as novas gerações e, de forma crítica, desenvolver métodos de educação apropriados às suas características; ao campo da orientação profissional com jovens impõe-se exigência semelhante.

Pode-se dizer que a socialização no universo digital será positiva na medida em que, tendo sua compreensão de mundo ampliada, juntamente com o desenvolvimento de uma consciência reflexiva das informações obtidas, o jovem consiga relacionar-se com as características da atual modernidade de uma forma saudável e responsável. A apropriação crítica e criativa das novas tecnologias da informação e comunicação (TIC) torna-se um elemento central para o exercício da cidadania, uma vez que as TIC "atuam em muitas esferas da vida social, não apenas com funções efetivas de controle social (político, ideológico...), mas também gerando novos modos de perceber a realidade, de aprender, de produzir e difundir conhecimentos e informações" (BÉVORT; BELLONI, 2009, p.1083). As TIC, desse modo, funcionam como instituições de socialização, uma espécie de "escola paralela". Contudo, se a relação que o adolescente estabelece com as informações disponíveis na internet não for 
orientada por certos critérios, se ele não souber filtrá-las e apropriar-se delas adequadamente, consequências negativas poderão ser observadas, dentre elas, o "embarcar", de forma alienada, na fluidez da modernidade líquida descrita por Bauman (2001). O próprio autor indica a tendência atual ao 'não aprender', ao esquecimento do que é conhecido (BAUMAN, 1999). O paradoxo que se apresenta ao adolescente é a exponencial proximidade da informação e o apelo a não absorção dessa informação.

\section{Orientação profissional no contexto atual: reflexões e novas possibilidades}

Diante dos dados da literatura a respeito dos obstáculos encontrados na atualidade pelos adolescentes na hora de fazer as primeiras escolhas profissionais e sobre a evasão universitária, associadas às proposições a respeito das características de fluidez da modernidade, propõe-se aqui uma reflexão sobre as dificuldades de apropriação e comprometimento nas relações que os jovens estão estabelecendo com as informações e com as escolhas que enfrentam, e o impacto disso para a intervenção em Orientação Profissional. Parte-se da observação de Walsh e Savickas (2005) de que o futuro da Psicologia Vocacional depende da sua capacidade de responder às mudanças na sociedade, ao oferecer modelos, métodos e materiais que permitam uma intervenção adaptada ao contexto atual.

Primeiramente, há a ideia de que a Orientação Profissional de adolescentes tem como objetivo principal fazer com que estes definam, da forma mais acertada possível, uma carreira ou trabalho a ser seguido. Contudo, é importante frisar que este processo é também uma possibilidade para o adolescente se conhecer melhor, ampliar e transformar a consciência que possui acerca de si mesmo, do mundo do trabalho e dos cursos e profissões pelos quais se interessa - tudo isso dentro de sua realidade sócio-histórica - tendo, dessa forma, melhores condições para fazer suas primeiras escolhas profissionais, assim como pensar e organizar seu projeto de vida como um todo, já que vida profissional e pessoal são esferas intrinsecamente ligadas e as escolhas de uma influem na outra (MELO-SILVA; OLIVEIRA; COELHO, 2002; SPARTA; BARDAGI; TEIXEIRA, 2006). A orientação profissional tem, portanto, assim como afirmam Melo-Silva e colaboradores (2002), a função de auxiliar o adolescente no processo de tomada de consciência sobre "quem ele quer ser", e deve possibilitar que os jovens aprendam a fazer suas escolhas da forma mais autônoma e consciente possível.

Contudo, fazer escolhas de forma autônoma e consciente é uma tarefa complexa e que pode ser difícil de ser cumprida diante das características da modernidade líquida apresentadas por Bauman (1999; 2001) e Haroch (2004; 
2005). Se, por um lado, o monitoramento reflexivo da ação apresenta-se como uma característica da modernidade, por outro, a fluidez contemporânea dificulta e até mesmo pode impedir a reflexão, pois com os fluxos sensoriais e informacionais contínuos, produzidos em grande parte pelas modernas exigências de intensa produtividade, o exercício da consciência estaria sendo reduzido, "intensificando a descontinuidade, a fragmentação, e aí a superficialidade, a ausência de discernimento" (HAROCH, 2005, p.349).

Em consonância com esta percepção, na prática, constata-se que os sujeitos em processo de escolha profissional apresentam dificuldades em estabelecer prioridades e hierarquias de interesses, em pensar em si mesmos no futuro e em comprometer-se com valores pessoais e projetos de vida. Considerando as diferentes dimensões envolvidas nos processos de orientação profissional com adolescentes, três delas foram selecionadas para a presente reflexão com base em uma hierarquia de relevância orientada pela experiência de duas décadas de atuação prática na área, pelas indicações presentes na literatura especializada e pela intensidade do impacto da fluidez presente na modernidade sobre as escolhas profissionais, a saber: as dimensões da informação profissional, do comportamento exploratório vocacional qualificado e da orientação para o futuro.

Chama a atenção o fato dos jovens contemporâneos apresentarem-se, paradoxalmente, substancialmente desinformados justamente na era da informação, na qual internet e outros diversos mecanismos proporcionam um acesso bastante amplo a uma série cada vez mais volumosa de conteúdos. Como advertem Bévort e Belloni (2009), as formas de apropriação das novas tecnologias da informação e comunicação precisam ser problematizadas, uma vez que as TIC se configuram como instituições de socialização hodiernas. Seria por conta da fluidez já mencionada que, justo na era da informação, os adolescentes parecem estar tão mal informados sobre questões relativas ao mundo do trabalho e tão pouco conscientes de suas próprias características? É importante ressaltar também que, obviamente, nem todas estas fontes necessariamente disponibilizam informações verídicas/realistas. Os adolescentes precisam, então, aprender a filtrar, aprofundar e se apropriar de uma forma crítica destas informações. Mas como seria possível mediar o desenvolvimento de competências para o uso da informação e da capacidade de transformá-la em conhecimentos úteis a esses sujeitos? Essa é, sem dúvida, uma questão demasiadamente ampla e complexa.

No que se refere especificamente à dimensão da informação profissional, Bock (2002) propõe que no processo de orientação profissional seja refletido a respeito da confiabilidade das informações disponíveis, bem como sejam evidenciados e discutidos os valores dominantes na sociedade, para que se estabeleça uma relação entre estes e a escolha profissional. A análise conjunta 
de peças publicitárias, novelas, filmes, entre outros materiais, na qual se procure extrair as mensagens implícitas das cenas apresentadas surge como uma possibilidade de atuação prática nessa direção. Tais cenas costumam passar mensagens que valorizam o poder, o prestígio, o dinheiro e o individualismo, valores que são relacionados ao poder de consumo e que influenciam a escolha profissional, os quais devem ser discutidos junto a outros valores que também a demarcam, como os vinculados ao compromisso social e à realização coletiva (LUNA, 2003) Deve-se, portanto, propor ao orientando que este analise, critique, relacione e estabeleça sua própria hierarquia entre estes valores, que pode estar ou não de acordo com a hierarquia dominante.

Relacionado à seleção e à reflexão críticas sobre as informações disponíveis, dentre os fatores importantes para que o processo de escolha profissional alcance bons resultados, destaca-se a dimensão do comportamento exploratório vocacional qualificado (LASSANCE; TEIXEIRA, 2010). O comportamento vocacional exploratório compreende as atividades realizadas a fim de reunir informações sobre si mesmo ou sobre o ambiente que ajudarão na escolha, preparação, entrada, ajustamento ou progresso em uma ocupação ou carreira. Contudo, nem todo tipo de experimentação e investigação conduz necessariamente a uma boa escolha; é preciso que haja também comprometimento por parte do orientando que proporcione reflexões profícuas sobre essas experiências, ou seja, é preciso que o comportamento exploratório seja qualificado (LASSANCE; TEIXEIRA, 2010), o que envolve um movimento que vai, evidentemente, de encontro à lógica "superficializante" da modernidade líquida.

A relevância da dimensão orientação para o futuro destaca-se, ainda, nos processos de orientação profissional, especialmente no desenvolvimento de carreira dos jovens, devido ao fato de estes estarem em uma etapa de ênfase na exploração de possibilidades de trabalho e formação, de capacidade de planejamento, decisão, elaboração de projetos pessoais e vocacionais (PAIXÃO, 2004; SAVICKAS; SILLING; SCHWARTZ, 1984; SUPER,1990). Relações positivas entre orientação temporal para o futuro e um conjunto de características vocacionalmente relevantes como adaptação acadêmica e atitude acadêmica positiva, exploração vocacional, autoestima e locus de controle interno, estabelecimento de metas de carreira e motivação dos estudantes têm sido verificadas, inclusive, em uma série de estudos (ABOUSSELAM, 2005; HORSTMANSHOF; ZIMITAT, 2007; JANEIRO; FERREIRA-MARQUES, 2010; NOBRE; JANEIRO, 2009).

Nesse sentido, a orientação profissional deve incluir atividades que promovam a orientação temporal para o futuro. Todavia, percebe-se um inicial paradoxo entre o processo da modernidade líquida, orientado ao presente, aos 
vínculos imediatos e superficiais, e a necessidade da orientação profissional proporcionar aos adolescentes uma perspectiva mais voltada ao futuro, à capacidade de antecipação e planejamento, à reflexão sobre preferências e interesses estáveis e duradouros, que embasem a construção de projetos individuais e sociais. Como as ações humanas transcendem às intenções deliberadas dos agentes (GIDDENS, 1989), mesmo na ausência de uma clara orientação para o futuro a vida segue; no entanto, nesses casos, o papel de protagonista dos sujeitos diante de suas trajetórias de vida pode ser questionado, ao mesmo tempo em que se multiplicam as chances de suas histórias pessoais serem conduzidas pelos ditames da atual modernidade.

Por fim, tendo em vista essas características de fluidez e falta de comprometimento presentes na modernidade, é possível concluir que o processo de orientação profissional de adolescentes se faz complexo, desafiador e, em relação ao passado recente, ainda mais necessário. Para que possa fazer escolhas consistentes e construir uma carreira satisfatória, será preciso que o adolescente tenha oportunidade e disposição para buscar e refletir a respeito de uma série de informações acerca do mundo do trabalho e de si próprio (seus interesses, valores, habilidades e aspirações), para realizar uma análise hierárquica relacionada a estas questões e para se comprometer com este processo. Certamente o desenvolvimento de uma carreira consistente e alinhada com os projetos profissionais de cada jovem poderá ser perturbado pelas dinâmicas flexíveis e incertas observadas atualmente no universo das organizações e do trabalho, bem como dependerá de uma série de fatores socioeconômicos relacionados ao acesso aos meios de autorrealização, que ainda se apresenta extremamente desigual na modernidade. Não obstante essa realidade, evidencia-se a relevância dos processos de orientação profissional enquanto "momentos de parada", propícios para a avaliação crítica de novas possibilidades com base no autoconhecimento reflexivo; ou melhor, em um contexto de modernidade líquida, a importância da orientação profissional apresenta-se de forma intensa e renovada.

O orientador profissional terá, entre outras tantas atividades, que auxiliar o adolescente especialmente na ampliação de seu autoconhecimento, uma vez que na atualidade os jovens encontram-se tão desprovidos de tempo e oportunidades para conhecer a si mesmos, e o autoconhecimento será fundamental para que eles saibam quem são e o que querem, para que possam, então, empreender escolhas consistentes com seus projetos de vida. Embora a necessidade de autoconhecimento esteja na base dos processos de orientação desde sua criação enquanto prática aplicada da psicologia, parece necessário, nesse novo contexto, que uma parcela significativa do tempo da orientação seja dedicada a ele. Também será preciso intensificar o auxilio ao jovem na 
qualificação de seu comportamento exploratório, ou seja, no aprendizado da filtragem, aprofundamento e apropriação das informações disponíveis, bem como na orientação temporal para o futuro, desafiando a "força do curto prazo". Isso envolverá a reflexão sobre a modernidade líquida e a construção de um pensamento crítico dos jovens sobre si mesmos e a respeito de suas realidades sócio-históricas, principalmente no que diz respeito à necessidade de "desaceleração", conscientização e comprometimento, seja na hora de escolher um curso, uma profissão, planejar sua carreira ou em qualquer outra circunstância.

\section{Considerações finais}

Os impactos das características da modernidade líquida nos processos de orientação profissional correspondem a uma temática praticamente inexplorada na literatura. Assim sendo, é possível que sua ampliação ainda revele diferentes contribuições que a orientação profissional pode vir a oferecer aos adolescentes do início do século XXI. Nessa direção, a possibilidade da identidade profissional, tendo como referência o domínio de um determinado conhecimento ou de uma habilidade específica (LUNA, 2005), servir como uma "ancora de carreira" que oriente os indivíduos em suas trajetórias profissionais, assim como o estudo das expectativas dos jovens quanto ao tipo de contrato psicológico que pretendem estabelecer com as organizações de trabalho, surgem como possíveis agendas de pesquisa sobre o tema.

No entanto, já se torna possível, nesse momento, conjecturar que é preciso que os processos de orientação profissional na atualidade auxiliem os jovens a lidar com a imprevisibilidade, com as mudanças rápidas e com o surgimento de novas possibilidades e novos interesses e preferências no campo do trabalho, bem como a distinguir o que é efêmero e o que é contínuo em termos de interesses e preferências, com base nos valores e competências pessoais essenciais. Destarte, é preciso criar um espaço de reflexão e de planejamento, voltado para a construção de futuros viáveis e satisfatórios, nas perspectivas individuais e coletivas, por mais que tal intuito entre em conflito com a estética do consumo e com a política da satisfação instantânea características da modernidade líquida.

Diante disto, propõe-se uma revisão da ênfase que é dada aos diferentes procedimentos geralmente adotados pelos profissionais de orientação profissional. A redistribuição do tempo dedicado aos diferentes momentos desse processo, no sentido de aumentar o tempo dedicado a atividades voltadas ao autoconhecimento e ao aprofundamento de reflexões a respeito da realidade contemporânea é uma possibilidade. 
A orientação profissional pode auxiliar os jovens em processo de escolha profissional ao proporcionar-lhes um ambiente no qual possam parar para pensar, onde possam aprender a filtrar, aprofundar e se apropriar de forma crítica das informações disponíveis. A orientação profissional pode se configurar, ainda, como um espaço no qual se problematize a realidade sócio-histórica, especialmente no que diz respeito à possível necessidade de "desaceleração", maior reflexão e comprometimento com as escolhas profissionais e com a vida pessoal e da sociedade como um todo. Não se trata de desconstruir as possibilidades de auxílio aos processos de escolha que as intervenções em orientação profissional já demonstraram de forma consistente (MELSERT; BICALHO, 2012; PINTO; CASTANHO, 2012), mas de pensar reformulações necessárias e assumir definitivamente o caráter político desta prática, no sentido de que ela contribui para a produção de novos modos de subjetivação ao problematizar os lugares instituídos.

De acordo com as proposições de Super, sintetizadas por Guichard e Huteau (2001), "um indivíduo está tanto satisfeito com sua existência quanto nela puder realizar suas capacidades, as suas necessidades, os seus valores, os seus interesses, os seus traços de personalidade e os seus conceitos de si" (GUICHARD; HUTEAU, 2001, p.182). Portanto, é função do orientador profissional propiciar que o sujeito aprenda a identificar o que terá de buscar para construir uma carreira que lhe traga essa satisfação, bem como favorecer a aprendizagem necessária à realização de escolhas e ao desenvolvimento de estratégias que permitam o alcance dos objetivos desejados.

Sendo assim, pode-se afirmar também que a Orientação Profissional é um importante instrumento de promoção de saúde. E ainda, para além da questão do bem-estar individual, assim como aponta Silva (2004), o orientador profissional também precisa estar atento à questão da necessidade de contribuir para o exercício da cidadania e para a melhora da qualidade da vida em sociedade. Desse modo, deve auxiliar os orientandos na superação das barreiras impostas à reflexão e à apropriação das informações, "atingindo uma conscientização do significado do trabalho como atividade social, num mundo em movimento, facilitando, assim, a construção de um pensamento crítico pelos sujeitos a respeito de sua realidade social, cultural, econômica" (SILVA, 2004, p.64). Dessa forma, a orientação profissional pode contribuir também com o processo de tomada de consciência, engajamento e comprometimento social.

\section{Referências}

ABOUSSELAM, Nicoletta Melina. The moderator effect of future time perspective in the relationship between self-efficacy and risky sexual behavior. 2005. Tese (Doutorado em 
Psicologia). Department of Psychology, Faculty of Humanities, University of The FreeState, Bloemfontein, South Africa, 2005.

BAPTISTA NETO, Francisco Baptista. O adolescente no início do século XXI. In: BAPTISTA NETO, Francisco Baptista; OSÓRIO, Luiz Carlos. (Orgs). Adolescentes: o desafio de entender e conviver. Florianópolis: Insular, 2011, p.21-28.

BARDAGI, Marucia Patta;HUTZ, Cláudio Simon Hutz. Não havia outra saída: percepções de alunos evadidos sobre o abandono do curso superior. Psico-USF, Itaiba, v. 14, n. 1, jan./abr. 2009.

BAUMAN, Zygmunt. Globalização: as consequências humanas. Rio de Janeiro: Zahar, 1999. Modernidade Líquida. Rio de Janeiro: Zahar, 2001.

BÉVORT, Evelyne; BELLONI, Maria Luiza. Mídia-Educação: conceitos, história e perspectivas. Educação e Sociedade, Campinas, v. 30, n. 109, p. 1081-1102, set./dez. 2009.

BOCK, Silvio Duarte. Orientação profissional: A abordagem sócio-histórica. Rio de Janeiro: Cortez, 2004.

CORCUFF, Philippe. As novas sociologias. Bauru: EDUSC, 2001.

ELIAS, Norbert. A sociedade dos indivíduos. Rio de Janeiro: Jorge Zahar Ed., 1994.

ERIKSON, Erik. Identidade: juventude e crise. Rio de Janeiro: Zahar, 1976.

FARIA, Luiz Roberto Paiva ; GUZZO, Raquel Souza Lobo. Em tempo de globalização: a representação social de emprego, trabalho e profissão em adolescentes. Estudos e Pesquisas em Psicologia, Rio de Janeiro, v. 7, n. 3, p. 387-404, dez. 2007.

FILHO, Roberto Leal; MOTEJUNAS, Paulo Roberto; HIPÓLITO, Oscar; LOBO, Maria Beatriz de Carvalho Melo. Evasão no ensino superior brasileiro. Cadernos de Pesquisa, São Paulo, v. 37 n.132, set/dez 2007.

GIDDENS, Anthony. A constituição da sociedade. São Paulo: Martins Fontes, 1989.

Modernidade e identidade. Rio de Janeiro: Zahar, 2002.

GUICHARD, Jean; HUTEAU, Michel. Psicologia da Orientação. Lisboa: Piaget, 2001.

HAROCH, Claudine. Crise da consciência contemporânea e expansão do saber não cumulativo. Educação e Pesquisa, São Paulo, v. 31, n. 3, set./dez. 2005.

. Maneiras de ser, maneiras de sentir do indivíduo hipermoderno. Ágora: Estudos em Teoria Psicanalítica, Rio de Janeiro, v. 7, p.2, jul/dez 2004.

HORSTMANSHOF, Louise; ZIMITAT, Craig. Future time orientation predicts academic engagement among first-year university students. British Journal of Educational Psychology, London, v. 77, n. 3, p. 703-718, set. 2007. 
JANEIRO, Isabel Nunes; FERREIRA-MARQUES, José. Career coping styles: Differences in career attitudes among secondary school students. International Journal of Educational and Vocational Guidance, v. 10, n.1, p. 35-48, mar. 2010.

KNOBEL, Maurício. A síndrome da adolescência normal. In: ABERASTURY, Arminda; KNOBEL, Maurício. (Orgs.) Adolescência normal: um enfoque psicanalítico. Porto Alegre: Artes Médicas, 1981, p. 24-59.

LASSANCE, Maria Célia Pacheco; TEIXEIRA, Marco Antônio Pereira. O trabalho no centro de avaliação psicológica, seleção e orientação profissional (CAP-SOP) - uma abordagem integrada. In: LASSANCE, M. C. P. (Org). Técnicas para o trabalho de orientação profissional em grupo. Porto Alegre: Editora UFRGS, 2010, p. 15-78.

LEHMAN, Yvette Piha. University students in crisis: University dropout and professional re-selection. Estudos de Psicologia, Campinas, n.31, v.1, p. 45-53, jan./mar, 2014.

LEVENFUS, Rosane Schotgues. Geração Zapping e o Sujeito da Orientação Vocacional. In: LEVENFUS, Rosane Schotgues; SOARES, Dulce Helena Penna. (Orgs) Orientação Vocacional Ocupacional. Porto Alegre: Artmed, 2002, p. 33-50.

LUNA, Iuri Novaes. Realização pessoal e realização coletiva: a responsabilidade da orientação profissional na construção da identidade profissional. In: MELO-SILVA, Lucy Leal; SANTOS, Manoel Antônio dos; SIMÕES, Joab Tenysson; AVI, Maira Cecília. (Orgs). Arquitetura de uma ocupação: orientação profissional: teoria e prática. São Paulo: Vetor, 2003, p. 91-96.

LUNA, Iuri Novaes. Para além das aparências: construção da identidade no mundo do trabalho. In: LASSANCE, Maria Célia Pacheco et al. (Orgs.). Intervenção e compromisso social (Vol. 2). São Paulo: Vetor, 2005, p.79-96.

MELO-SILVA, Lucy Leal; OLIVEIRA Josiane Calixto de; COELHO, Reginaldo de Souza. Avaliação da Orientação profissional no desenvolvimento da maturidade na escolha da profissão. Revista de Psicologia da Vetor, [S.1.], v. 3 n. 2, p. 44-53, 2002.

MELSERT, Ana Luísa de Marsillac; BICALHO, Pedro Paulo Gastalho de. Desencontros entre uma prática crítica em psicologia e concepções tradicionais em educação. Revista Semestral da Associação Brasileira de Psicologia Escolar e Educacional, São Paulo, v. 16, n. 1, p. 153160. jan./jun. 2012.

NOBRE, Ana Sofia Rodrigues; JANEIRO, Isabel Nunes. Relação entre a Perspectiva Temporal e a Adaptação à Escola em alunos do $9^{\circ}$ ano. In: SIMPÓSIO NACIONAL DE INVESTIGAÇÃO EM PSICOLOGIA, 7, Braga, Portugal, 4 a 6 fev. 2010, Actas... Universidade do Minho, Braga, Portugal, 2010, p. 3033-3043.

OLIVEIRA, Maria Claudia Santos Lopes de. Identidade, narrativa e desenvolvimento na adolescência: uma revisão crítica. Psicologia em Estudo, Maringá, v. 11, n. 2, p. 427-436, mai./ ago. 2006.

OLIVEIRA, Adriano Machado; TOMAZETTI, Elisete Medianeira. Quando a sociedade de consumidores vai à escola: um ensaio sobre a condição juvenil no Ensino Médio. Educar em Revista, Curitiba, n. 44, p. 181-200, abr./jun. 2012. 
SANTOS, M. M.; LUNA, I. N.; BARDAGI, M. P. O desafio da orientação profissional com adolescentes...

PAIXÃO, Maria Paula. A dimensão temporal do futuro na elaboração de objectivos pessoais e organização de projectos vocacionais. Psychologica, [S.1.], extra-série, p. 273-286, 2004.

PAREDES, Alberto Sanchez. A evasão do terceiro grau em Curitiba. 23p. NUPES/USP, São Paulo, documento de trabalho n. 6/1994. Disponível em: <http://nupps.usp.br/downloads/docs/ dt9406.pdf $>$. Acesso em: 7 ago. 2012.

PINTO, Telma Maranhão Gomes; CASTANHO, Marisa Irene Siqueira. Sentidos da escolha e da orientação profissional: um estudo com universitários. Estudos de Psicologia. Campinas, v. 29 n.3, p. 395-413, jul./set. 2012.

PRADO, Luiz Carlos Delorme. Globalização: notas sobre um conceito controverso. IE-UFRJ, 2001. Disponível em< https://xa.yimg.com/kq/groups/24059305/64393181/name/01+texto+2009.1+AEG.pdf.> Acesso em: 17 dez. 2014.

PRENSKY, Marc. Digital natives, digital immigrants. On the Orizon (MCB, University Press), v.9, n.5, p. 1-6, oct. 2001.

PRIMI, R. et al. Desenvolvimento de um inventário de levantamento das dificuldades da decisão profissional. Revista Psicologia Reflexão e Crítica, Porto Alegre, v. 13 n. 3, p. 451-463, 2000 .

SAVICKAS, Mark L.; SILLING, Marc; SCHWARTZ, Steven. Time perspective in vocational maturity and career decision making. Journal of Vocational Behavior, [S.1.], v. 25, p. 258269, 1984.

SCHIESSE, Cláudia Schead; SARRIERA, Jorge Castellá. O ingresso à universidade: Dificuldades e expectativas dos jovens em relação à escolha do curso universitário. Psico, v. 31, n. 2, p. 123-146, 2000.

SENNETT, Richard. A Cultura do novo capitalismo. 2 ed. Rio de Janeiro: Record, 2008.

A corrosão do caráter: consequências pessoais do trabalho no novo capitalismo. Rio de Janeiro: Record, 2002.

SILVA, Janaila dos Santos. A influência dos meios de comunicação social na problemática da escolha profissional: o que isso suscita à psicologia no campo da orientação vocacional / profissional? Psicologia Ciência e Profissão, Brasília, v. 24, n. 4, p. 60-67, 2004.

SOARES, Francisco Luiz Batista. A escolha no ensino superior: fatores de decisão. 2007, 125f. Dissertação (Mestrado em Economia). Programa de Pós-Graduação em Economia. Universidade Federal do Rio Grande do Sul, Porto Alegre, 2007.

SPARTA, Mônica; BARDAGI, Marúcia Patta; ANDRADE, Ana Maria Jung de. Exploração vocacional e informação profissional percebida em estudantes carentes. Aletheia, [S.1.], n. 22, p. 79-88, jul./dez, 2005.

SPARTA, Mônica; BARDAGI, Marúcia Patta; TEIXEIRA, Marco Antônio Pereira. Modelos e instrumentos de avaliação em orientação profissional: perspectiva histórica e situação no Brasil.

Revista Brasileira de Orientação Profissional, Ribeirão Preto, v. 7, n. 2, p. 19-32, 2006. 
SUPER, Donald Edwin. A Life-span, Life-space to career development. In: BROWN, D; BROOKS, L. (Orgs). Career choice and development. Applying contemporary theories to practice. San Francisco: Jossey Bass, 1990, p.197-261.

WALSH, Walsh Bruce; SAVICKAS, Mark L. Current issues and innovations in vocational psychology. In: WALSH, Walsh Bruce; SAVICKAS, Mark L. (Orgs). Handbook of vocational psychology: Theory, research and practice 3rd ed. Hillsdale, NJ: Lawrence Erlbaum Associates, 2005, p. 3-11.

Submissão em: 11/03/2013

Revisão em: 27/04/2014

Aceite em: 20/07/2014

/

Mariana Moura dos Santos é Psicóloga pela UFSC. Residente do Programa de Residência Integrada Multiprofissional em Saúde do Hospital Universitário da UFSC.

Endereço para correspondência: Laboratório de Informação e Orientação Profissional da UFSC, sala 14A, Departamento de Psicologia, CFH, Campus João David Ferreira Lima, Trindade, CEP 88040-900. E-mail: mariana.mrsnt@gmail.com

Iuri Novaes Luna é Psicólogo, Doutor em Sociologia Política pela UFSC. Professor adjunto do curso de Psicologia e do Programa de Pós-Graduação em Psicologia da UFSC. E-mail: iuri.luna@ufsc.br

Marucia Patta Bardagi é Psicóloga, Doutora em Pscicologia (UFRGS). Professora adjunta do curso de Psicologia da UFSC e do PPGPsicologia UFSC. Coordenadora do Laboratório de Informação e Orientação Profissional da UFSC 